\title{
Telmisartan attenuates isoproterenol-induced cardiac remodeling in rats via regulation of cardiac adiponectin expression
}

\author{
Bing-yan GUO ${ }^{1}$, Yong-jun $\mathrm{LI}^{1,}$ *, Rui HAN${ }^{2}$, Shao-ling YANG ${ }^{4}$, Ying-hui SHI ${ }^{3}$, De-rong HAN ${ }^{3}$, Hong ZHOU ${ }^{1}$, Mei WANG $^{1}$ \\ ${ }^{1}$ Department of Cardiovascular Medicine, Second Affiliated Hospital, Hebei Medical University, Shijiazhuang 050017, China; ${ }^{2}$ Depart- \\ ment of Internal Neurology Medicine, First Affiliated Hospital, Hebei Medical University, Shijiazhuang 050017, China; ${ }^{3}$ Department \\ of Internal Medicine, Gucheng County Hospital, Gucheng 253800, China; ${ }^{4}$ Department of Endocrinology Medicine, Norman Bethune \\ International Peace Hospital, Shijiazhuang 050031, China
}

\begin{abstract}
Aim: To investigate whether telmisartan (Telm) pretreatment attenuates isoproterenol (Iso)-induced postinfarction remodeling (PIR) in rats, and whether the effect of Telm is associated with cardiac expression of adiponectin.

Methods: PIR was induced in male Wistar rats with two consecutive injections of Iso $(80 \mathrm{mg} / \mathrm{kg}, \mathrm{sc})$ at an interval of $24 \mathrm{~h}$. Primary culture of ventricular myocytes from neonatal rats was prepared. Iso-induced cardiomyocyte injury was assessed based on cell growth and lactate dehydrogenase (LDH) activity. Cardiac adiponectin expression was measured using qRT-PCR and immunoblot analysis.

Results: In the rats with PIR, Telm (10 $\mathrm{mg} \mathrm{kg}^{-1} \cdot \mathrm{d}^{-1}$, po for $\left.65 \mathrm{~d}\right)$ suppressed Iso-induced increases in gravimetric parameters, cardiomyocyte diameter and collagen volume fraction, but had no effect on Iso-induced myocardial hypertrophy and interstitial fibrosis. The protective effect of Telm was associated with enhanced protein expression of cardiac adiponectin. In cultured cardiomyocytes, Telm (5-20 $\mu \mathrm{mol} / \mathrm{L})$ inhibited the cell death and LDH release induced by Iso $(10 \mu \mathrm{mol} / \mathrm{L})$, and reversed Iso-induced reduction in adiponectin protein expression. In cardiomyocytes exposed to Iso $(20 \mu \mathrm{mol} / \mathrm{L})$, GW9662 (30 $\mu \mathrm{mol} / \mathrm{L})$, a selective antagonist of PPAR- $y$, blocked the effects of Telm pretreatment on adiponectin protein expression, as well as the protective effects of Telm on Iso-induced cell injury. Conclusion: Telm attenuates Iso-induced cardiac remodeling and cell injury, which is associated with induction of cardiac adiponectin expression.
\end{abstract}

Keywords: telmisartan; angiotensin II receptor blocker; congestive heart failure; cardiac remodeling; cardiac fibrosis; adiponectin; isoproterenol

Acta Pharmacologica Sinica (2011) 32: 449-455; doi: 10.1038/aps.2010.231; published online 14 Mar 2011

\section{Introduction}

There are a variety of experimental models of chronic heart failure (CHF). Isoproterenol (Iso)-induced CHF is a widely used model due to its simple methodology, low cost, and the clinically representative pathophysiological changes it produces. In this model, subcutaneous administration of the beta adrenoceptor agonist Iso produces patchy myocardial necrosis in a dose-related manner while retaining intact coronary vasculature. The pathophysiological and morphological changes observed in Iso-treated rats have been found to be similar to those observed following human myocardial infarction $(\mathrm{MI})^{[1]}$. MI results in asymmetrical left ventricular remodeling, characterized by fibrosis at both the site of infarct and in

\footnotetext{
* To whom correspondence should be addressed.

E-mail lyjbs2009@yeah.net

Received 2010-06-23 Accepted 2010-12-23
}

the noninfarcted myocardium, in addition to hypertrophy of viable myocytes ${ }^{[2]}$. These cardiac structural adaptations facilitate compensated hemodynamic performance, but ultimately result in a high incidence of $\mathrm{CHF}$ and sudden cardiac death ${ }^{[3]}$.

Adiponectin acts as an anti-inflammatory and antiatherogenic cytokine and has been demonstrated to suppress cardiac hypertrophy in response to pressure overload ${ }^{[4,5]}$. Adiponectin, a member of the adipokine superfamily, is expressed in adult ventricular cardiomyocytes and is upregulated by activation of peroxisome proliferator-activated receptor-gamma $(\text { PPAR- } \gamma)^{[6]}$. Adiponectin was recently shown to be suppressed by tumor necrosis factor-alpha (TNF- $\mathrm{a})^{[7]}$, another cytokine that is expressed in and secreted from cardiomyocytes ${ }^{[8]}$. Locally generated TNF-a plays a role in cardiac remodeling via its ability to stimulate apoptosis and inflammatory and fibrogenic responses in a pressure-overloaded heart, which in turn contribute to cardiac dysfunction ${ }^{[9,10]}$. 
Telmisartan (Telm) is a selective angiotensin II type 1 receptor antagonist that is widely used in the treatment of hypertension, CHF, and diabetic nephropathy ${ }^{[11-13]}$. It has been shown to have beneficial effects on postinfarct ventricular remodeling ${ }^{[14]}$. Recently, Telm was reported to have partial activity as a PPAR- $\gamma$ agonist, enabling it to regulate metabolic and inflammatory pathways and improve left ventricular functions ${ }^{[15,16]}$. Moreover, Telm treatment has been shown to reduce the expression of inflammatory cytokines, including TNF- $\alpha$ and its transcription factors ${ }^{[17-19]}$. Angiotensin receptor blocker (ARB) treatment increases circulating adiponectin concentrations in humans and adiponectin mRNA levels in adipose tissue in hypertensive rats ${ }^{[20-23]}$. ARB treatment also induces cardiac adiponectin expression in mice with viral myocarditis $^{[24]}$. In addition, Telm was recently shown to be present in plasma at higher levels than other ARBs following oral administration ${ }^{[25]}$, suggesting that it is absorbed well when administered orally. To date, however, the effects of Telm on cardiac adiponectin have not been studied.

The present study was designed to investigate the cardioprotective effects of Telm in vitro and in vivo, specifically its effects on cardiac adiponectin and TNF-a. We also examined the necessity of PPAR- $\gamma$ activity in the stimulatory effects of Telm on adiponectin expression in cardiomyocytes. Cardiomyocyte viability and lactate dehydrogenase (LDH) activation, which is released when cell injury occurs, were employed as indexes of injury severity in our in vitro experiments.

\section{Materials and methods \\ Animals}

Forty male Wistar rats (200-250 g body weight; 6-8 weeks of age) were obtained from the Experimental Animal Center of Hebei Medical University. This research was carried out in accordance with the National Research Council protocol for the care and use of laboratory animals. The animals were housed in the Laboratory Animal Center under conditions of a controlled ambient temperature of $22-24^{\circ} \mathrm{C}$ with a 12 -h light/ dark cycle. Animals were provided with free access to standard rodent chow and tap water and were allowed to acclimate for a period of $7 \mathrm{~d}$.

\section{Drugs and chemicals}

Telm was obtained from Boehringer Ingelheim International $\mathrm{GmbH}$ (Germany). Iso hemisulfate was dissolved in 0.9\% saline and used within $10 \mathrm{~min}$ of preparation. All chemicals used in this study were of analytical grade and purchased from Sigma Chemicals (St Louis, MO, USA).

\section{Induction of cardiac remodeling}

To induce PIR, rats were administered two subcutaneous injections of $80 \mathrm{mg} / \mathrm{kg}$ homologous Iso (Sigma-Aldrich) or vehicle at $24 \mathrm{~h}$ intervals on 2 consecutive days, as described by Palfi A et al ${ }^{[26]}$.

\section{Experimental groups}

After $7 \mathrm{~d}$ of acclimatization, the experimental animals were divided into the following treatment groups: 1) Iso, $n=10 ; 2$ ) Iso+Telm, $n=10$; 3) Telm, $n=10$; and 4) control (vehicle), $n=10$. Rats in the Telm and Iso+Telm groups were administered Telm orally $\left(10 \mathrm{mg} \cdot \mathrm{kg}^{-1} \cdot \mathrm{d}^{-1}\right)$ by intragastric intubation for a period of $65 \mathrm{~d}$. All rats were fed a standard diet throughout this experimental period. Changes in body weight and food and water intake were noted for all animals at regular intervals throughout the experimental period.

\section{Tissue preparation}

Two months after the last Iso injection, each rat was weighed and sacrificed by intravenous injection of $2-3 \mathrm{~mL}$ of $10 \% \mathrm{KCl}$ through the femoral vein. Immediately after the $\mathrm{KCl}$ injection, the thorax was opened and the heart was excised, rinsed with saline, blotted dry, and weighed. The left ventricle (LV) was dissected out by incising the right ventricle along the septum and then weighed. Heart weight to body weight and LV weight to body weight ratios were calculated. One segment of the LV was then fixed in $4 \%$ paraformaldehyde and embedded in paraffin. The other segment was rapidly frozen in liquid nitrogen and stored at $-80^{\circ} \mathrm{C}$ for further analysis.

\section{Histological examination and Masson staining}

After being fixed for $24 \mathrm{~h}$ in $4 \%$ paraformaldehyde, the tissue blocks were dehydrated and embedded in paraffin; 5 - $\mu$ m-thick sections were then cut and stained with either hematoxylin-eosin or Masson's trichrome stain. Eight light microscope visual fields were randomly selected for each Masson's trichome stained section and viewed using a computer-assisted image analysis system (Motic Med 6.0 CMIAS, China). To assess cardiomyocyte diameter, the crosssectional margins of cardiomyocytes in the LV were marked with the cursor using the Image Pro Plus 4.1 software and the mean diameter was calculated; only cardiomyocytes that had complete cell boundaries and clear round intra-cytoplasmic nuclei were measured. Approximately 60-70 cardiomyocytes were randomly selected from five to seven images captured randomly at different sites in each specimen and the average cross-sectional diameter was calculated. The collagen volume fraction (CVF) was measured in five fields for each LV section. CVF values were determined by quantitative morphometry using an automatic image analyzer (IBAS 2.5, Kontron, Germany), such that $\mathrm{CVF}=$ fibrosis area/total area of myocardium. The CVF excluded scars and perivascular collagen areas. The pathologist performing the histopathological evaluations was blinded to the treatment group designations.

\section{Primary culture of neonatal rat ventricular myocytes (NRVMs)}

NRVMs were prepared as described previously ${ }^{[27]}$. Briefly, ventricles from 1-3 d-old Wistar rats were minced and digested in phosphate-buffered saline (PBS) containing $0.1 \%$ trypsin and $0.04 \%$ type II collagenase for $8-10$ cycles. The degraded tissue was then centrifuged and suspended in Dulbecco's modified Eagle's medium containing 15\% fetal bovine serum. A single 2-h preplating step was performed to further increase the ratio of NRVMs to noncardiomyocytes. Noncar- 
diomyocytes attached readily to the bottom of culture dishes, and the unattached myocytes were plated at $1 \times 10^{6}$ cells $/ \mathrm{cm}^{2}$ in the same medium as above and supplemented with 0.1 $\mathrm{mmol} / \mathrm{L}$ BrdU. Cells were then held in serum-free medium for $24 \mathrm{~h}$ prior to being used in experiments. Morphological examination and staining with an anti-sarcomeric a-actin antibody were carried out to confirm the presence of NRVMs, with about $95 \%$ of the cells being identified as NRVMs.

\section{Cell growth assay}

The cytotoxic effect of Iso on cardiac myocytes was measured using the MTT assay as described elsewhere ${ }^{[28]}$. The cells were dispensed in 96-well flat bottomed microtiter plates (NUNC, Roskilde, Denmark) at a density of $5 \times 10^{5}$ cells/well. After $48 \mathrm{~h}$ of incubation, the cells were treated with Iso $(10 \mu \mathrm{mol} / \mathrm{L})$ and/ or various concentrations of Telm for $48 \mathrm{~h}$. Cell viability was calculated as follows:

Viability $(\%)=\left(A_{490, \text { sample }}-A_{490, \text { blank }}\right) /\left(A_{490, \text { control }}-A_{490, \text { blank }}\right) \times 100$

\section{LDH activity-based cytotoxicity assay}

LDH content released into the culture medium was measured as an index of LDH activity. The cells were incubated with various concentrations of Telm for $1 \mathrm{~h}$ prior to a $48 \mathrm{~h}$ incubation in the presence of isoproterenol $(10 \mu \mathrm{mol} / \mathrm{L})$. The substrate reaction buffer for $\mathrm{LDH}[0.5 \mathrm{mmol} / \mathrm{L}$, with or without lactic acid, $0.66 \mathrm{mmol} / \mathrm{L}$ INT, $0.28 \mathrm{mmol} / \mathrm{L}$ PMS, and 1.3 mmol/ $\mathrm{L} \mathrm{NAD}^{+}$in Tris-HCl, $\mathrm{pH}$ 8.2] was added to collected samples of culture media. The absorbance value $(A)$ at $490 \mathrm{~nm}$ for the LDH reaction was assayed after 1 and $5 \mathrm{~min}$.

\section{Measurements of protein expression levels in myocardium and} cultured cardiomyocytes

For immunoblot analysis, extracts of myocardial tissue and treated cells were matched for protein concentration $(15 \mu \mathrm{g})$ with SDS-PAGE sample buffer, separated by SDS-PAGE, and transferred to a polyvinylidene difluoride membrane. The membranes were incubated with the indicated primary antibodies overnight at $4{ }^{\circ} \mathrm{C} ; 50 \mu \mathrm{g}$ of denatured protein was subjected to sodium dodecyl sulfate polyacrylamide gel electrophoresis (SDS-PAGE) on a 10\% polyacrylamide gel (BioRad, Hercules, CA, USA) and transferred to polyvinylidene difluoride (PVDF) membranes (Bio-Rad, Hercules, CA, USA) for detection of adiponectin levels. Nonspecific binding was prevented by incubation with $5 \%$ nonfat dry milk for $1 \mathrm{~h}$. The PVDF membranes were incubated overnight at $4{ }^{\circ} \mathrm{C}$ with antiAcrp30 and anti-GAPDH primary antibodies diluted in TBS-T (1:1000) (Santa-Cruz Biotechnology, Santa Cruz, CA, USA). After washing in Tween-20 buffer, the membranes were incubated with fluorescent secondary antibodies. Labeling was quantified using the Odyssey Infrared Imaging System (LI-COR Biosciences, Lincoln, USA). Acrp30 expression was corrected by comparison to the endogenous control GAPDH. Band densities were scanned and quantified using a LEICA550IW image analysis system.

\section{Statistical analysis}

All data are expressed as mean \pm SD. Group mean values were compared using one-way analysis of variance (ANOVA) followed by a Tukey's multiple comparison test where appropriate. For all comparisons, $P<0.05$ was used to establish statistically significant results.

\section{Results \\ Influence of Telm on Iso-induced effects on gravimetric parameters}

The gravimetric parameters in hearts of intact and PIR animals are presented in Figure 1. Rats treated with Iso alone showed significantly elevated heart mass normalized to body mass, while Iso-treated rats that had been pretreated with Telm did not show these unfavorable changes (Figure 1A). Telm pretreatment also reduced the gain in Iso-induced ventricular mass (Figure 1B). Heart mass and ventricle/body mass ratio did not differ between rats treated with Telm alone and control (no drug) rats (Figure 1).
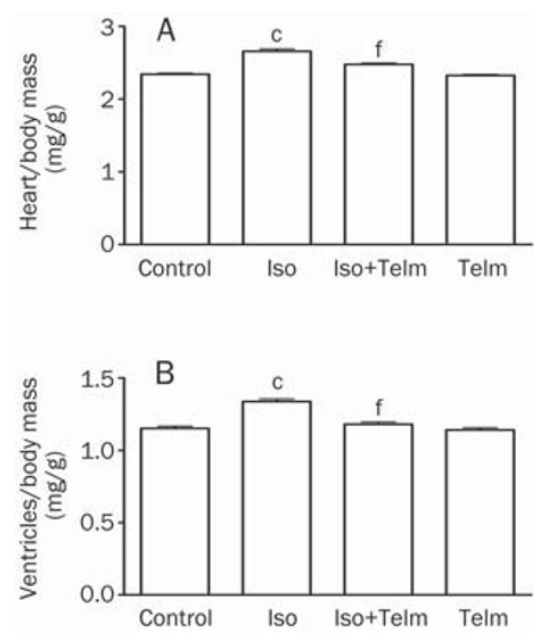

Figure 1. Effects of Telm and Iso on the gravimetric parameters in rats with PIR. Mean \pm SD. $n=10$. ${ }^{\mathrm{c}} P<0.01$ vs control group; ${ }^{\mathrm{f}} P<0.01$ vs Iso group.

\section{Impact of Telm on Iso-induced myocardial hypertrophy and} interstitial fibrosis

Compared to untreated PIR (isoprotrenol alone) animals, PIR animals given Telm showed significantly attenuated Isoinduced increases in mean myocyte diameter (Figure 2) and collagen volume fraction (Figure 3). Treatment with Telm alone had no effect on these values $(P>0.05$ vs control) (Figure 2,3).

Protective effects of Telm against PIR are associated with enhanced protein expression of adiponectin

Relative to intact hearts, TNF-a expression in hearts with PIR was increased by about three-fold $(P<0.01)$ while adiponectin expression in hearts with PIR was decreased by about half 

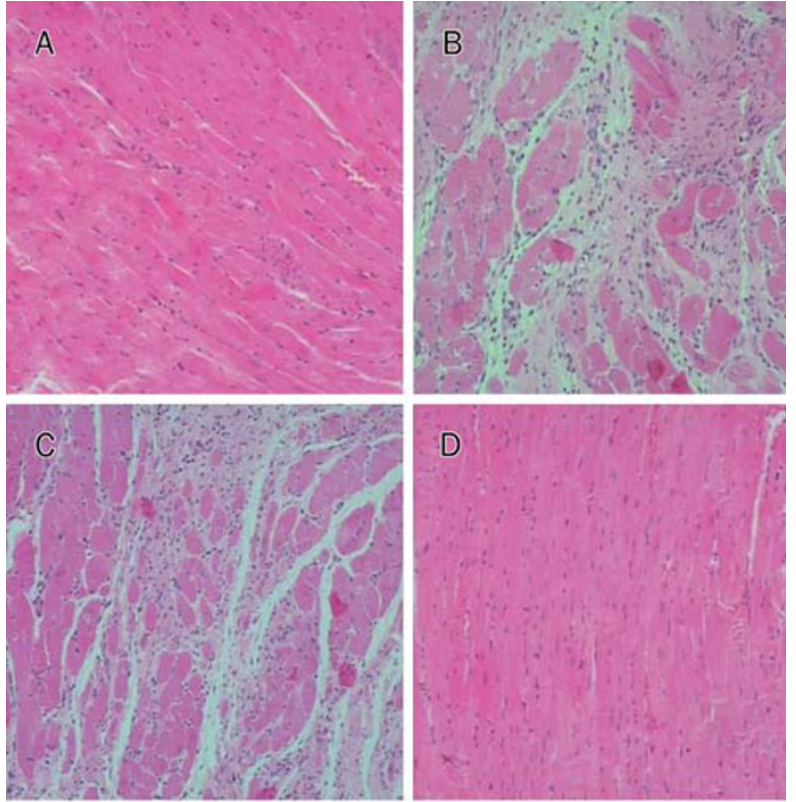

E

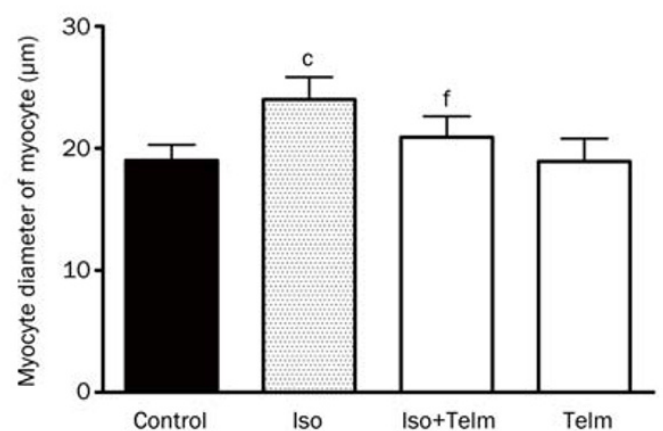

Figure 2. Effects of Telm and Iso on myocardial hypertrophy in rats with PIR. (A) control group; (B) Iso group; (C) Iso+Telm group; (D) Telm group; (E) Quantitative analysis of the myocyte diameter. Mean \pm SD. $n=10 .{ }^{c} P<0.01$ vs control group; ${ }^{\text {f }} P<0.01$ vs Iso group.

$(P<0.01)$ (Figure 4). Oral administration of Telm significantly attenuated these PIR-related changes in TNF- $\alpha$ and adiponectin expression (Figure 4).

\section{Telm inhibits Iso-induced cell death in cardiomyocytes}

Cardiomyocytes were exposed to Iso $(10 \mu \mathrm{mol} / \mathrm{L})$ alone, Iso $(10 \mu \mathrm{mol} / \mathrm{L})$ with Telm $(5-20 \mu \mathrm{mol} / \mathrm{L})$, or vehicle for $48 \mathrm{~h}$. The cell death inhibition ratio of Telm-treated cells relative to Iso only-treated cells ranged from $40.2 \% \pm 4.5 \%$ (5 $\mathrm{mmol} / \mathrm{L}$ Telm) to $92.6 \% \pm 7.1 \%(20 \mu \mathrm{mol} / \mathrm{L}$ Telm) (Figure $5 \mathrm{~A})$. Telm protected Iso-treated cardiomyocytes from cell death in a dose-dependent manner and had no cytotoxic effects on the cells.

It is worth noting that we observed a marked increase in the cardiomyocyte beating rate $6 \mathrm{~h}$ after Iso treatment. The cardiomyocyte beating rate was then weakened in a timedependent manner such that by $48 \mathrm{~h}$ following Iso treatment, no cell beating was observed. On the contrary, cells that were exposed to Telm and Iso simultaneously continued to exhibit

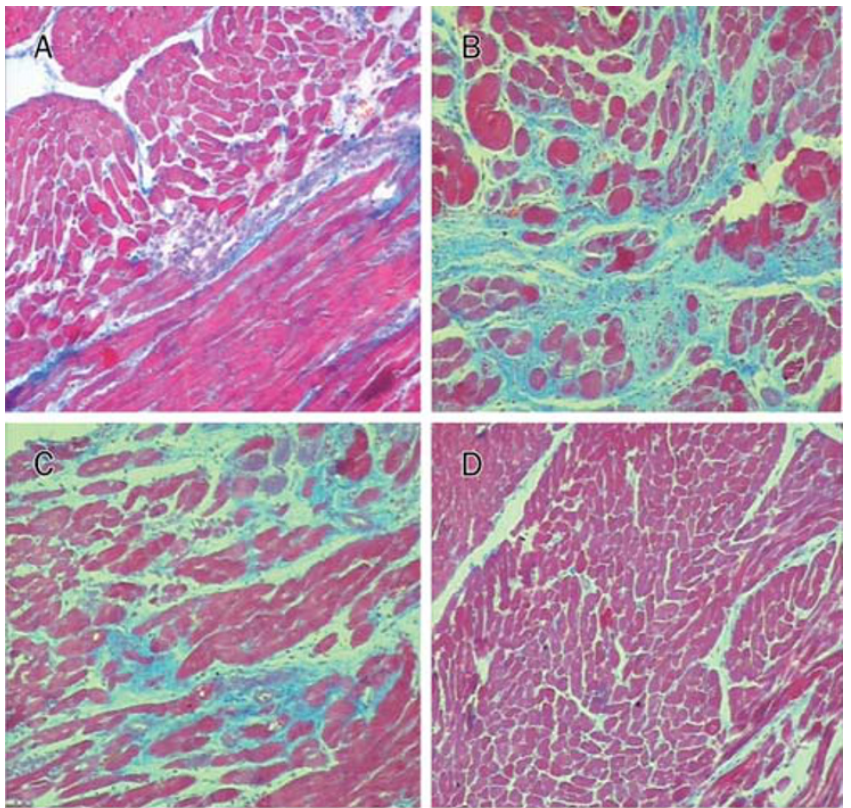

$E$

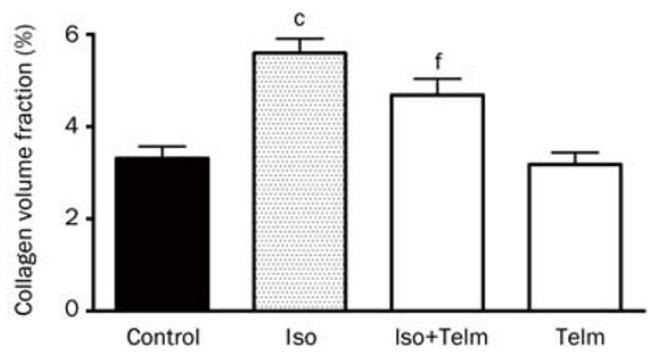

Figure 3. Effects of Telm and Iso on collagen volume fraction (CVF) in rats with PIR. (A) control group; (B) Iso group; (C) Iso+Telm group; (D) Telm group; (E) Quantative analysis of the CVF. Mean \pm SD. $n=10 .{ }^{c} P<0.01$ vs control group. ${ }^{f} P<0.01$ vs Iso group.

steady beating throughout the $48 \mathrm{~h}$ experimental period.

Telm inhibited Iso-induced LDH release in cardiomyocytes

Iso $(10 \mu \mathrm{mol} / \mathrm{L})$ nearly doubled LDH release in cardiomyocytes relative to cells not exposed to any drug $(P<0.01)$. Pretreatment with Telm for $48 \mathrm{~h}$ reduced Iso-induced $\mathrm{LDH}$ release in a dose-dependent manner; at $20 \mu \mathrm{mol} / \mathrm{L}$, Telm-pretreated, Iso-exposed cells had LDH release levels that were similar to those of untreated control cells (Figure 5B). Telm alone (5-20 $\mu \mathrm{mol} / \mathrm{L}$ ) did not affect $\mathrm{LDH}$ release (data not shown).

Telm treatment blocked Iso effects on adiponectin protein expression in cardiomyocytes via a mechanism involving PPAR-y activation

After incubation with $10 \mu \mathrm{mol} / \mathrm{L}$ Iso, adiponectin protein expression in cardiomyocytes was decreased relative to cells not exposed to any drug. However, in cells that were pretreated with Telm $(20 \mu \mathrm{mol} / \mathrm{L})$, this decrease did not occur. Treating Iso-exposed cells with the selective PPAR- $\gamma$ antagonist GW9662 (30 $\mathrm{mol} / \mathrm{L})$ potently blocked the effects of Telm 

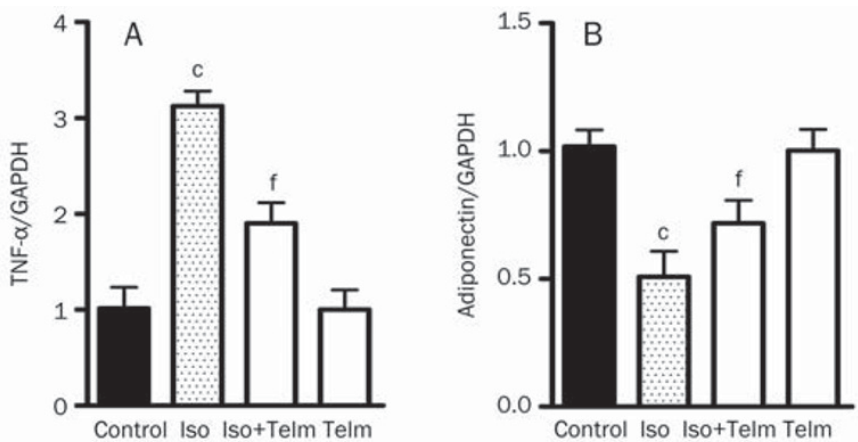

C

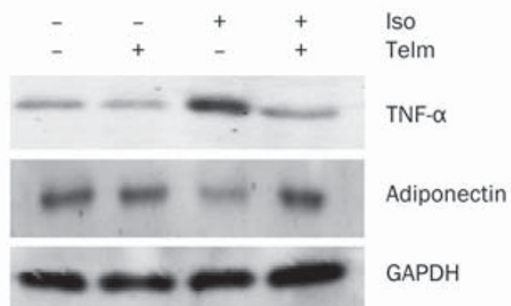

Figure 4. Effects of Telm and Iso on protein expression of cardiac adiponectin and TNF- $\alpha$ in rat hearts with PIR. GAPDH was used as a loading control. Mean \pm SD. $n=10 .{ }^{c} P<0.01$ vs control group. ${ }^{f} P<0.05$ vs Iso group.
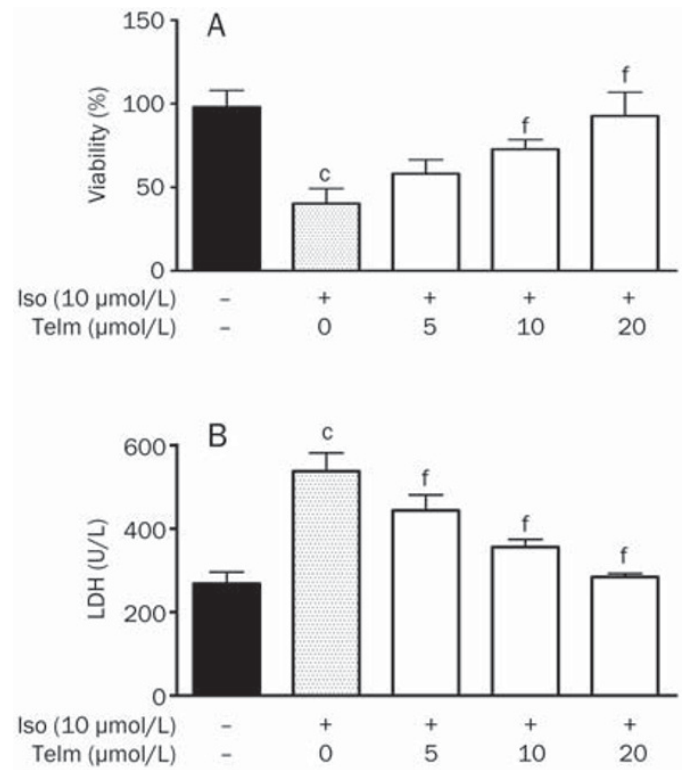

Figure 5. Telm protects against Iso-induced myocardial cell injury. Cells were incubated with Telm with or without Iso $(10 \mu \mathrm{mol} / \mathrm{L})$ for $48 \mathrm{~h}$. (A) Cell viability was evaluated using the MTT method. (B) LDH activity was measured in the culture medium. Mean \pm SD. $n=4 .{ }^{\circ} P<0.05$ vs control group. ${ }^{f} P<0.01$ vs Iso only group.

pretreatment on adiponectin expression (Figure 6). GW9662 in the absence of Telm did not change the Iso-induced decrease of adiponectin expression (data not shown).
Adiponectin
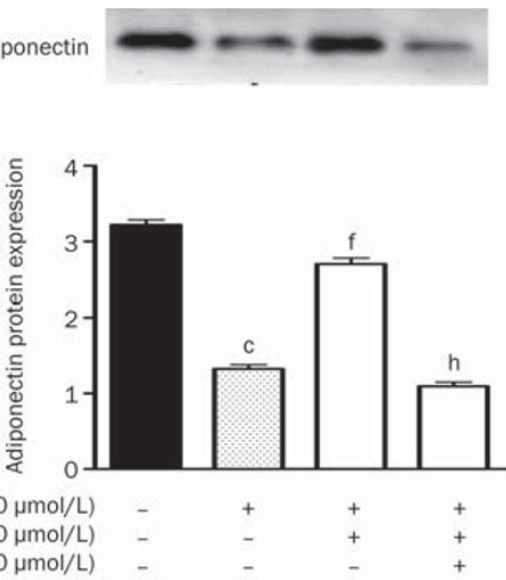

Figure 6. Telm upregulates adiponectin protein expression in Iso-treated cardiomyocytes via PPAR-y activation. Cardiocytes were pre-incubated for $1 \mathrm{~h}$ in the presence or absence of the PPAR-y antagonist GW9662 (30 $\mu \mathrm{mol} / \mathrm{L}$ ), and were then incubated in the presence or absence of Iso (10 $\mu \mathrm{mol} / \mathrm{L})$ and/or Telm $(20 \mu \mathrm{mol} / \mathrm{L})$ for the subsequent $24 \mathrm{~h}$. Adiponectin protein levels were then measured immediately by immunoblot analysis. Protein levels are expressed relative to non-treated control cells $(n=3)$. ${ }^{c} P<0.05$ vs control group. ${ }^{\mathrm{f}} P<0.01$ vs Iso only group. ${ }^{\mathrm{h}} P<0.05$ vs Iso+Telm group.

Inhibiting PPAR-y activity with the selective antagonist GW9662 blocked the protective effects of Telm against Iso-induced cell injury

Inhibition of PPAR-y activity with the selective antagonist GW9662 $(30 \mu \mathrm{mol} / \mathrm{L})$ potently blocked the protective effects of Telm against Iso-induced cell injury (Figure 7A and 7B). GW9662 alone (in the absence of Telm) had no observable effects on Iso-induced cell injury (data not shown).

\section{Discussion}

In the present study, oral Telm pretreatment prevented changes in gravimetric parameters and reduced myocardial hypertrophy and interstitial fibrosis in Iso-induced PIR hearts. Oral Telm pretreatment also reversed MI-induced decreases in adiponectin expression as well as MI-induced increases in TNF-a expression. Cardiac expression of adiponectin mRNA negatively correlated with expression of cardiac TNF-a mRNA. Importantly, heart size and interstitial fibrosis were not influenced by Telm in non-PIR hearts, and Telm led to an increased performance of the postinfarct heart. Cardiomyocytes treated in vitro with Iso alone showed elevated LDH activity accompanied by markedly inhibited cell growth; Telm inhibited Iso-induced cell death and LDH release in cardiomyocytes. Furthermore, we demonstrated that administration of the PPAR- $\gamma$ antagonist GW9662 blocked the stimulatory effects of Telm on adiponectin expression in cardiomyocytes. The ability of Telm to promote preservation of myocardial adiponectin expression may represent an important mechanism for the beneficial effects of Telm in PIR.

Our demonstration that PPAR- $\gamma$ activity was necessary for Telm-induced reversal of Iso-induced decreases in adiponectin 
A

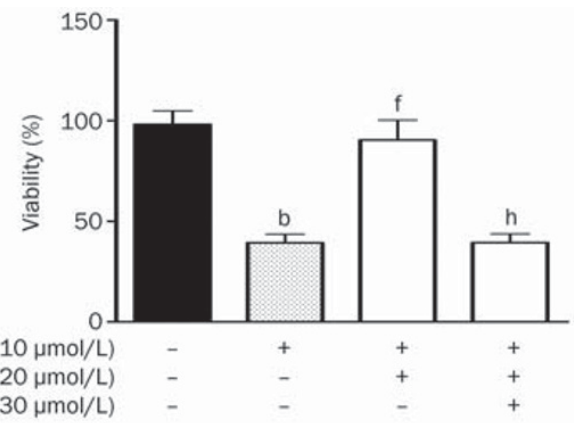

B

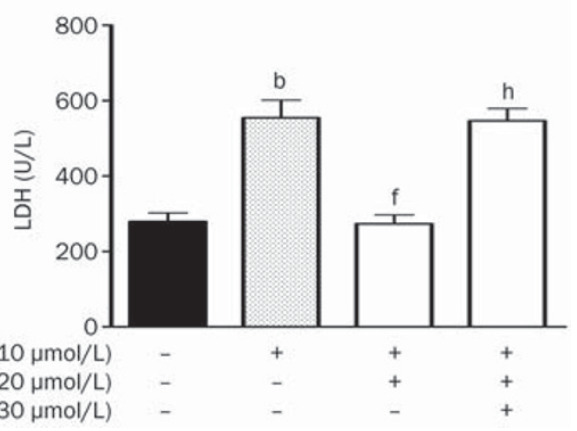

Figure 7. Effects of the selective PPAR-y antagonist GW9662 on the inhibitory action of Telm on Iso-induced cardiomyocyte injury. Cardiomyocytes were pretreated with GW9662 (30 $\mathrm{mol} / \mathrm{L})$, then incubated with Iso $(10 \mu \mathrm{mol} / \mathrm{L})$ and Telm $(20 \mu \mathrm{mol} / \mathrm{L})$. Treated cells were then subjected to measurements of cell viability $(A)$ and LDH activity (B). Mean \pm SD. $n=4$. ${ }^{b} P<0.05$ vs control group. ${ }^{f} P<0.01$ vs Iso group. ${ }^{\mathrm{h}} \mathrm{P}<0.05$ vs Iso+Telm group.

protein expression complements the recent findings of Goyal et $a l^{[29]}$, suggesting that Telm exerts its protective effects against Iso-induced cardiac injury in vivo in two ways, functioning as an ARB as well as a PPAR- $\gamma$ activator. Moreover, activated PPAR- $\gamma$, which has anti-inflammatory and antioxidant effects $^{[30]}$, has been shown to stimulate adiponectin expression in adipocytes and to upregulate adiponectin plasma levels in animals and humans ${ }^{[31,32]}$.

Our findings showing increased expression of cardiac TNF-a protein accompanied by decreased expression of adiponectin in the presence of myocardial injury are consistent with prior studies suggesting that the two factors may work in opposition to each other. For example, adiponectin has been shown to provide protection against TNF-a-mediated myocardial injury and apoptosis in animal models of $\mathrm{MI}^{[33]}$. Furthermore, adiponectin knockout mice show elevated TNF-a expression, which can be attenuated by adiponectin ${ }^{[34]}$. Thus, TNF-a and adiponectin appear to have an antagonistic relationship, with one cytokine negatively regulating the expression of the other $^{[35]}$.

After MI, initial loss of the myocardium can induce progressive ventricular enlargement and deposition of interstitial collagen, changes which are intended to adapt the heart to its altered situation. However, increased muscle mass is achieved by the enlarging of cardiomyocytes rather than an increase in their number, which together with the increased interstitial fibrosis ultimately impairs heart performance and decreases its elasticity. Recently, inflammatory pathways and a pro-inflammatory cytokine mechanism have been invoked to explain Iso-induced PIR through the promotion of matrix metalloproteinase expression in cardiac fibroblasts ${ }^{[36]}$. These post-MI changes contribute to the progression toward $\mathrm{CHF}$, characterized by a progressive deterioration in heart function. Autopsies have revealed the presence of adiponectin in the interstitium of early stage MI lesions, and the presence of adiponectin was further found to lie linearly along the border of vital myocardium and at the periphery of surviving cardiomyocytes around lesions in granulation stage MI lesions ${ }^{[37]}$. Expression of adiponectin has also been reported in the injured myocardium of patients with cardiomyopathy ${ }^{[38]}$. Our study reveals for the first time that the protective effects of Telm in vivo and in vitro are associated with enhanced expression of cardiac adiponectin. Thus we posit that Telm may induce cardiac adiponectin expression in the remodeling of hearts and in injured cardiomyocytes.

In summary, we have demonstrated that Telm treatment attenuates Iso-induced PIR in rats and exerts protective effects on Iso-treated rat cardiomyocytes. The cardioprotective actions of Telm may be mediated by the activation of ARB/ PPAR- $\gamma /$ adiponectin pathways and appear to involve cardiac expression of the anti-inflammatory cytokine, adiponectin, together with suppression of the inflammatory cytokine, TNF-a. The precise cardiac adiponectin-regulated signaling that occurs during Iso-induced PIR has yet to be delineated.

\section{Author contribution}

Yong-jun LI and Bing-yan GUO designed the study; Bingyan GUO, Rui HAN, Shao-ling YANG, Hong ZHOU, and Mei WANG performed the research; Yong-jun LI, Ying-hui SHI, and De-rong HAN contributed new analytical tools and reagents; Bing-yan GUO analyzed the data; and Bing-yan GUO wrote the paper.

\section{References}

1 Devika PT, Stanely Mainzen Prince P. Protective effect of (-)-epigallocatechingallate (EGCG) on lipid peroxide metabolism in ISO induced myocardial infarction in male Wistar rats: a histopathological study. Biomed Pharmacother 2008; 62: 701-8.

2 Sun Y, Zhang JQ, Zhang J, Lamparter S. Cardiac remodeling by fibrous tissue after myocardial infarction. J Lab Clin Med 2000; 135: 31623.

3 Palfi A, Toth A, Hanto K, Deres P, Szabados E, Szereday Z, et al. PARP Inhibition prevents postinfarction myocardial remodeling and heart failure via the protein kinase $\mathrm{C} /$ glycogen synthase kinase-3 beta pathway. J Mol Cell Cardiol 2006; 41: 149-59.

4 Matsuzawa Y. Therapy insight: adipocytokines in metabolic syndrome and related cardiovascular disease. Nat Clin Pract Cardiovasc Med 2006; 3: 35-42.

5 Shibata R, Ouchi N, Ito M, Kihara S, Shiojima I, Pimentel DR, et al. Adiponectin-mediated modulation of hypertrophic signals in the heart. Nat Med 2004; 10: 1384-9.

6 Ding G, Qin Q, He N, Francis-David SC, Hou J, Liu J, et al. Adiponectin 
and its receptors are expressed in adult ventricular cardiomyocytes and upregulated by activation of peroxisome proliferator-activated receptor-gamma. J Mol Cell Cardiol 2007; 43: 73-84.

7 Wulster-Radcliffe MC, Ajuwon KM, Wang J, Christian JA, Spurlock ME. Adiponectin differentially regulates cytokines in porcine macrophages. Biochem Biophys Res Commun 2004; 316: 924-9.

8 Neumann FJ, Ott I, Gawaz M, Richardt G, Holzapfel H, Jochum M, et al. Cardiac release of cytokines and inflammatory responses in acute myocardial infarction. Circulation 1995; 92: 748-55.

9 Doughty RN, Whalley GA, Walsh HA, Gamble GD, Lopez-Sendon J, Sharpe N. Effects of carvedilol on left ventricular remodeling after acute myocardial infarction: the CAPRICORN Echo Substudy. Circulation 2004; 109: 201-6.

10 Sun M, Dawood F, Wen WH, Chen M, Dixon I, Kirshenbaum LA, et al. Excessive tumor necrosis factor activation after infarction contributes to susceptibility of myocardial rupture and left ventricular dysfunction. Circulation 2004; 110: 3221-8.

11 Yamana A, Arita M, Furuta M, Shimajiri Y, Sanke T. The angiotensin II receptor blocker telmisartan improves insulin resistance and has beneficial effects in hypertensive patients with type 2 diabetes and poor glycemic control. Diabetes Res Clin Pract 2008; 82: 127-31.

12 Grassi G, Quarti-Trevano F, Mancia G. Cardioprotective effects of telmisartan in uncomplicated and complicated hypertension. J Renin Angiotensin Aldosterone Syst 2008; 9: 66-74.

13 Bakris G, Burgess E, Weir M, Davidai G, Koval S. AMADEO Study Investigators. Telmisartan is more effective than losartan in reducing proteinuria in patients with diabetic nephropathy. Kidney Int 2008; 74: 364-9.

14 Geng DF, Wu W, Jin DM, Wang JF. Effect of peroxisome proliferator activated receptor gamma ligand rosiglitazone on left ventricular remodeling in rats with myocardial infarction. Int J Cardiol 2006; 113: 86-91.

15 Benson SC, Pershadsingh HA, Ho Cl, Chittiboyina A, Desai P, Pravenec $\mathrm{M}$, et al. Identification of telmisartan as a unique angiotensin II receptor antagonist with selective PPARgamma-modulating activity. Hypertension 2004; 43: 993-1002.

16 Schupp M, Janke J, Clasen R, Unger T, Kintscher U. Angiotensin type 1 receptor blockers induce peroxisome proliferator-activated receptorgamma activity. Circulation 2004; 109: 2054-7.

17 Wu L, Iwai M, Nakagami H, Li Z, Chen R, Suzuki J, et al. Roles of angiotensin II type 2 receptor stimulation associated with selective angiotensin II type 1 receptor blockade with valsartan in the improvement of inflammation-induced vascular injury. Circulation 2001; 104: 2716-21.

18 Lorenzo O, Ruiz-Ortega M, Suzuki Y, Rupérez M, Esteban V, Sugaya T, et al. Angiotensin III activates nuclear transcription factor-kappaB in cultured mesangial cells mainly via AT(2) receptors: studies with AT(1) receptor-knockout mice. J Am Soc Nephrol 2002; 13: 1162-71.

19 Berthonneche C, Sulpice T, Tanguy S, O'Connor S, Herbert JM, Janiak P, et al. AT1 receptor blockade prevents cardiac dysfunction after myocardial infarction in rats. Cardiovasc Drugs Ther 2005; 19: 2519.

20 Fujioka D, Kawabata K, Saito Y, Kobayashi T, Nakamura T, Kodama $\mathrm{Y}$, et al. Role of adiponectin receptors in endothelin-induced cellular hypertrophy in cultured cardiomyocytes and their expression in infarcted heart. Am J Physiol Heart Circ Physiol 2006; 290: H240916.

21 Yilmaz MI, Sonmez A, Caglar K, Celik T, Yenicesu M, Eyileten T, et al. Effect of antihypertensive agents on plasma adiponectin levels in hypertensive patients with metabolic syndrome. Nephrology 2007; 12: $147-53$
22 Lely AT, Krikken JA, Bakker SJ, Boomsma F, Dullaart RP, Wolffenbuttel $\mathrm{BH}$, et al. Low dietary sodium and exogenous angiotensin II infusion decrease plasma adiponectin concentrations in healthy men. J Clin Endocrinol Metab 2007; 92: 1821-6.

23 Zorad S, Dou JT, Benicky J, Hutanu D, Tybitanclova K, Zhou J, et al. Long-term angiotensin II AT(1) receptor inhibition produces adipose tissue hypotrophy accompanied by increased expression of adiponectin and PPARgamma. Eur J Pharmacol 2006; 552: 112-22.

24 Saegusa S, Fei Y, Takahashi T, Sumino H, Moriya J, Kawaura K, et al. Oral administration of candesartan improves the survival of mice with viral myocarditis through modification of cardiac adiponectin expression. Cardiovasc Drugs Ther 2007; 21: 155-60.

25 Lasek W, Wańkowicz A, Kuc K, Feleszko W, Giermasz A, Jakóbisiak M. Augmentation of antitumor efficacy by the combination of actinomycin D with tumor necrosis factor-alpha and interferon-gamma on a melanoma model in mice. Oncology 1996; 53: 31-7.

26 Palfi A, Bartha E, Copf L, Mark L, Gallyas F Jr, Veres B, et al. Alcoholfree red wine inhibits ISO-induced cardiac remodeling in rats by the regulation of Akt1 and protein kinase C alpha/beta II. J Nutr Biochem 2009; 20: 418-25.

27 Ouchi N, Shibata R, Walsh K. Cardioprotection by adiponectin. Trends Cardiovasc Med 2006; 16: 141-6.

28 Benson SC, Pershadsingh HA, Ho Cl, Chittiboyina A, Desai P, Pravenec $\mathrm{M}$, et al. Identification of telmisartan as a unique angiotensin II receptor antagonist with selective PPARgamma-modulating activity. Hypertension 2004; 43: 993-1002.

29 Goyal S, Arora S, Mittal R, Joshi S, Nag TC, Ray R, et al. Myocardial salvaging effect of telmisartan in experimental model of myocardial infarction. Eur J Pharmacol 2009; 619: 75-84.

$30 \mathrm{Yi} \mathrm{JH}$, Park SW, Brooks N, Lang BT, Vemuganti R. PPARgamma agonist rosiglitazone is neuroprotective after traumatic brain injury via antiinflammatory and anti-oxidative mechanisms. Brain Res 2008; 1244: 164-72.

31 Combs TP, Wagne JA, Berger J, Doebber T, Wang WJ, Zhang BB, et al. Induction of adipocyte complement-related protein of 30 kilodaltons by PPARgamma agonists: a potential mechanism of insulin sensitization. Endocrinology 2002; 143: 998-1007.

32 Fasshauer M, Paschke R, Stumvoll M. Adiponectin, obesity, and cardiovascular disease. Biochimie 2004; 86: 779-84.

33 Kapadia SR, Oral H, Lee J, Nakano M, Taffet GE, Mann DL. Hemodynamic regulation of tumor necrosis factor-alpha gene and protein expression in adult feline myocardium. Circ Res 1997; 81: 187-95.

34 Maeda N, Shimomura I, Kishida K, Nishizawa H, Matsuda M, Nagaretani $\mathrm{H}$, et al. Diet-induced insulin resistance in mice lacking adiponectin/ACRP30. Nat Med 2002; 8: 731-7.

35 Lihn AS, Richelsen B, Pedersen SB, Haugaard SB, Rathje GS, Madsbad S, et al. Increased expression of TNF-alpha, IL-6, and IL-8 in HALS: implications for reduced adiponectin expression and plasma levels. Am J Physiol Endocrinol Metab 2003; 285: E1072-80.

36 Li L, Wu L, Wang C, Liu L, Zhao Y. Adiponectin modulates carnitine palmitoyltransferase-1 through AMPK signaling cascade in rat cardiomyocytes. Regul Pept 2007; 139: 72-9.

37 Ishikawa Y, Akasaka Y, Ishii T, Yoda-Murakami M, Choi-Miura NH, Tomita $\mathrm{M}$, et al. Changes in the distribution pattern of gelatin-binding protein of $28 \mathrm{kDa}$ (adiponectin) in myocardial remodelling after ischaemic injury. Histopathology 2003; 42: 43-52.

38 Takahashi T, Saegusa S, Sumino H, Nakahashi T, Iwai K, Morimoto $\mathrm{S}$, et al. Adiponectin, T-cadherin and tumor necrosis factor-alpha in damaged cardiomyocytes from autopsy specimens. J Int Med Res 2005; 33: 236-44. 